\title{
Wie Geschichten Geschichte schreiben
}

\author{
Frühchristliche Literatur zwischen Faktualität und Fiktionalität \\ Hrsg. v. Susanne Luther, Jörg Röder u. Eckart David Schmidt
}

Wie Geschichten

Geschichte schreiben

Herausgegeben von

SUSANNE LUTH

JÖRG RŐDER

ECKART D. SCHMIDT

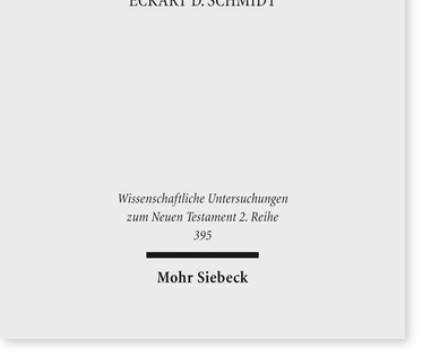

2015. VI, 452 Seiten. WUNT II 395

ISBN 978-3-16-153381-5

DOI 10.1628/978-3-16-153381-5

eBook PDF 119,00€

ISBN 978-3-16-152634-3

fadengeheftete Broschur $119,00 €$
Neuere sprachphilosophische und literaturwissenschaftliche Einflüsse auf die Geschichtswissenschaft fordern zu neuen Lektüren frühchristlicher Texte im Hinblick auf das Verhältnis von Faktualität und Fiktionalität. Die Beiträge dieses Bandes reflektieren diese Impulse aus wissenschaftstheoretischer Sicht und führen frühchristliche Texte in diesen Diskurs ein: Wie werden faktuale und fiktionale Weisen der literarischen Repräsentation für Erzählfiguren, Ereignisse, Themen und Motive umgesetzt? Welche Absichten werden dadurch verfolgt? Welche Effekte erzielt? Einblicke in den Metadiskurs und die Rezeptionsgeschichte zum Thema runden den Band ab.

Inhaltsübersicht

Susanne Luther/Jörg Röder/Eckart D. Schmidt: Fiktivität, Fiktionalität und Faktualität in der frühchristlichen Literatur - Eine Einführung

I. Auf dem Weg zu einer Theorie von Faktualität und Fiktionalität Jörg Röder: Zum Verhältnis von Faktualität und Fiktionalität. Ein Forschungsüberblick - Frank Zipfel: Fiktion und fiktionales Erzählen aus literaturtheoretischer Perspektive Vera Nünning: Unzuverlässiges Erzählen als Paradigma für die Unterscheidung zwischen faktualem und fiktionalem Erzählen

II. Frühchristliche Texte in der Diskussion Olaf Rölver: Der Blick des Begeisterten. Die Schrift als symbolische Form der matthäischen Jesuserzählung - Felix Albrecht: Herodes der Große und der Kindermord zu Bethlehem (Mt 2,16-18) aus historischer und narratologischer Perspektive - Thomas Schumacher: Die Taufe Jesu als Auferstehungserzählung des Markusevangeliums - Susanne Luther: Fiktionalitäts- und Faktualitätskriterien. Ein Versuch am Beispiel neutestamentlicher Wundererzählungen - Paul Metzger: Der Lieblingsjünger und die normative Kraft des Fiktiven - Kanonische Fiktionalität als fundamentaltheologisches Problem - Ruben Zimmermann: »Und der das gesehen hat, der hat es bezeugt, und sein Zeugnis ist wahr « (Joh 19,35) - Augenzeugenschaft im Johannesevangelium als hermeneutisches Konzept - Nils Neumann: Rhetorik

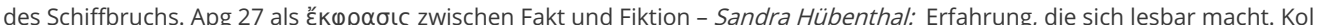
und 2 Thess als fiktionale Texte - Peter-Ben Smit: Back to the Future - Aspekte der Pseudepigraphie des Titusbriefes und ihre Bedeutung

III. Metadiskurse und Wirkungszusammenhänge Martin Bauspieß: Die Pragmatik der Geschichte. Der Metadiskurs zur Geschichtsschreibung in neutestamentlicher Zeit und die Diskussion nach dem »linguistic turn« - Eckart D. Schmidt: Ein aufgeklärter Jesus in der Neuen Welt. Die Bibelkompilationen Thomas Jeffersons: Historische Faktualität als Paradigma der Aufklärungsexegese?

Susanne Luther Born 1979; 2012 Dr. theol.; 2018 Habilitation; 2018-20 Assistant Professor of New Testament and Early Christian Studies at the Faculty for Theology and Religious Studies, University of Groningen (NL); since 2020 Professor of New Testament at the University of Göttingen. https://orcid.org/0000-0003-2593-4777

Jörg Röder Born 1980; since 2014 Researcher for the HyperNT Project (New Testament Studies), University of Basel.

Eckart David Schmidt Geboren 1969; Privatdozent für Neues Testament an der Theologischen Fakultät der Ruprecht-KarlsUniversität Heidelberg.

Jetzt bestellen:

https://mohrsiebeck.com/buch/wie-geschichten-geschichte-schreiben-9783161533815?no cache=1

order@mohrsiebeck.com

Telefon: +49 (0)7071-923-17

Telefax: +49 (0)7071-51104 